\title{
Openness to Experience, a Personality Trait of Gifted Adolescents and One of the Key Factors of High Developmental Potential
}

\author{
Mia Frumau-van Pinxten, Jan Derksen, Willy Peters \\ Faculty of Social Sciences, Radboud University, Nijmegen, the Netherlands
}

Email address:

miafrumau@gmail.com (M. Frumau-van P.)

\section{To cite this article:}

Mia Frumau-van Pinxten, Jan Derksen, Willy Peters. Openness to Experience, a Personality Trait of Gifted Adolescents and One of the Key Factors of High Developmental Potential. International Journal of Secondary Education. Vol. 9, No. 3, 2021, pp. 74-85.

doi: $10.11648 /$ j.ijsedu.20210903.11

Received: June 12, 2021; Accepted: June 28, 2021; Published: July 9, 2021

\begin{abstract}
The purpose of this study was to enhance our understanding of what motivates gifted individuals. The focus was on how the personality traits of highly gifted and gifted adolescents differ from those of adolescents with above-average intelligence. In a longitudinal self-report study, the following traits were considered: Openness to Experience (Imagination), Conscientiousness, Extraversion, Agreeableness (Benevolence), and Neuroticism. In addition, Strengths and Difficulties were assessed as an indicator of mental health. Participants were 561 highly gifted, gifted, and adolescents with above-average intelligence. Data was collected in grades 8 and 10. (R)MANOVAs were conducted with the Wilks' Lambda statistic to investigate the difference between the three cognitive capacity groups in personality traits and Strengths and Difficulties. The findings showed highly gifted and gifted adolescents to differ significantly from cognitively above-average adolescents on two personality traits, namely: Openness to Experience and Conscientiousness. Openness to Experience increased significantly more from grade 8 to grade 10 for the both the highly gifted adolescents and gifted adolescents compared to the adolescents with above-average intelligence, moreover. These findings in addition to the findings that the lower-order facets of the personality trait Openness to Experience, namely Intellect and Curiosity, characterize the highly gifted and gifted adolescents more than adolescents with above-average intelligence are in keeping with the findings of other countries. Finally, the highly gifted females and gifted adolescents in grade 10 in our study scored higher (i.e., above average) on the lower-order Concentration facet of the personality trait Conscientiousness than the highly gifted males and adolescents with above-average intelligence. In line with our expectations, the adolescents in this study all reported comparable levels of emotional stability, agreeableness, difficulties, and positive or pro-social behavior on average. The present findings suggest that Curiosity should be recognized and stimulated in gifted young people as one of the key aspects of high developmental potential.
\end{abstract}

Keywords: Gifted, Personality, Openness for Experience, High Developmental Potential, Strengths \& Difficulties

\section{Introduction}

Implicit theories about the personality characteristics of gifted people abound but are typically based on passing observation and only a small aspect of behavior. For example, teachers have been reported to characterize gifted students as more open to new experiences but at the same time more introverted, less emotionally stable, and less agreeable than other students [2].

Questions such as "Why do gifted individuals behave as they do?" and "What motivates them?" have yet to be considered in terms of established personality theory and models [34]. In light of what we know as therapists but also on the basis of relevant personality theory, we therefore set out to better understand the gifted adolescent and, in particular, how their high developmental potential distinguish them from other adolescents.

The theoretical framework of our research is based upon four components: the psychosocial identity development theory of the ego-psychologist Erikson, the Theory of Positive Disintegration (TPD) of Dabrowski, the Integrated Information Theory (IIT) of Tononi and the Five Factor Model 
of personality (FFM).

First, Erikson viewed the ego as the self-observing and self-organizing center of the person and the key to a healthy identity [13]. In developmental psychology, the importance of the experience of conflict for diverse aspects of identity development is widely accepted today and due to Erikson's recognition of the positive role of the experience of crisis [33].

Second, TPD places emotions central in personality development. The experience of negative emotions (e.g., tension and anxiety) is essential for advanced psychological development. When tragedy strikes and our previous sense of self (i.e., identity) is swept away, our greatest potential for growth manifests itself. When we question not only what we know but who we are, we can pick up those pieces of ourselves that we want to keep and discard those that we do not want to construct a new authentic identity [22].

Third, every complex, linked (not isolated) mechanism whose network system codes for causal relationships, possesses the same properties and thus has a certain degree of consciousness. Consciousness feels like something that comes from within. Consciousness is the powerful dynamic that emanates from complex connections within the human brain. IIT assigns a value to the complexity of the underlying network structure: a positive number $\Phi$ (phi) indicates the degree to which a system is conscious. When $\Phi$ equals zero, the system has no sense of self. The higher the $\Phi$, the stronger the intrinsic causal dynamics of the network system and the greater the degree of consciousness: The brain shows an extraordinarily large and heavily intertwined structure and therefore a very high $\Phi$-value and high degree of consciousness [31].

Fourth, the well-researched and well-established Five-Factor Model of personality (FFM) has been found to be valid across ages and cultures, and it thus provides an excellent starting point for examining the personality characteristics of gifted adolescents [34]. The five identified personality factors are: Openness to Experience (e.g., creativity, imagination, eagerness to learn); Conscientiousness (e.g., goal orientation, orderliness, trustworthiness, ambition, self-discipline); Extraversion (e.g., energy and dominance as opposed to being reserved, withdrawn, and submissive); Agreeableness (e.g., trust, sincerity, compassion as opposed to aggressiveness and egocentrism); and Neuroticism (e.g., emotional stability as opposed to self-doubt, general feelings of anxiety, and depression) (OCEAN). This model is also described as the "Big Five" although there is a difference between the Big Five and the FFM in the wording of the trait Openness to Experience. Costa and $\mathrm{McCrae}$ [4] based their factors on self-reports of behavior and they named one factor 'Openness to Experience'. The Big Five refers to lexical hypotheses [14] and names a comparable factor 'Intellect'. Both factors may be related constructs: Openness/Intellect. The FFM does not claim to be a complete theory of personality [11].

Personality traits visible in early but also later childhood and adolescence have been found to be continuous and stable. Throughout adolescence and young adulthood, moreover, the stability of personality traits increases in a relatively linear fashion [8]. Only IQ (i.e., cognitive ability) has been found to be more stable over time than personality traits [3].

Based on this four-component theoretical framework, a new definition of high developmental potential was formulated in 2020 by first author W. L. Frumau-van Pinxten:

A high developmental potential (HDP) entails the following elements:

1a) High sensory perception allowing an unusually large amount of information to be perceived and processed in depth.

1b) Heightened consciousness as a result of brain showing an extraordinarily large and heavily intertwined capacity (and thus a very high $\Phi$-value).

2) The personality trait Openness to Experience entailing intellectual curiosity, preference for novelty and variation, active imagination, aesthetic sensitivity, intense absorption in activities, toleration and cultivation of ambiguity, and awareness of inner emotions.

3) Embracement of negative emotions and conflict as possible sources of growth.

Element 1 (heightened perception and consciousness) is the motor driving high developmental potential.

Elements 2 and 3 (Openness to Experience and acknowledgement of conflict/crisis) are fuel for high developmental potential and explain the heightened sensitivity and intensity of the individual with a high developmental potential.

The fullness of the development of the individual's high potential is shaped by social experiences and other external and internal factors.

Measurements: Behavior can be measured -to a certain extent- using various capacity tests (1a.) and $\mathrm{OE}$ by a personality test (2) (e.g., HiPIC -children and adolescents- or FFPI -adults- $[24,18])$.

Our investigation aims to find some answers to the general question "What motivates gifted adolescents?" by measuring the behavior of gifted adolescents by using capacity tests and a personality test. We also are interested in investigating the above mentioned definition on high developmental potential.

Our investigation is longitudinal (grade 8,10,12 and young adulthood) and started with capacity tests. Due to our interest in high development potential, we opted for a set of two capacity tests (investigating 1a of the definition on HDP). The first test used was the Intelligenz Struktur Test (IST), which is a standardized group test [1] administered to all students in grade 7 by the Dutch Center for Giftedness $(C B O)$. In the present research, we additionally administered the Dutch version of the Raven advanced progressive matrices scale $(A P M)$ [27]. The Raven tests appeal to general reasoning skills, which are important for both verbal (linguistic) and non-verbal assignments. These skills are closely related to the $g$-factor, e.g. the most profound aspect of intelligence. In addition, the working memory is used during this test. We chose the APM-version, because this version has less than other capacity tests a ceiling for high intelligence. We divided the participants into three groups based on their cognitive capacity as measured by the two tests: highly gifted, gifted and above average intelligent adolescents. 
In order to further investigate the behavior of gifted adolescents (and also element 2 of the definition on HDP) we aimed to use an instrument to compare and describe personality traits of adolescents. De Clercq and de Fruyt [6, 9] were one of the first to extend the Five Factor model of personality to adolescence. Parallels between general measures of personality in adolescence and adulthood were confirmed [7]. They developed the Hierarchical Personality Inventory for Children (HiPIC, a lexically based and age-specific FFM personality inventory) [24]. And the factors identified using this inventory are sometimes referred to as the "Little Five". Only minor differences have been found between the Little and Big Five personality factors (e.g., The Benevolence trait from the Little Five model is conceptually most related to the Agreeableness trait in the Big Five model. However, within the trait Agreeableness, the lower-order facets compliance, irritability and dominance refer for the parents the manageability of their children).

Literature review showed a relationship, with a small to medium effect size between Openness to Experience and cognitive intelligence in the general population as well as in a gifted population compared to non-gifted population samples [34]. The association of intelligence with Openness to
Experience for gifted adolescents is confirmed but also were gifted adolescents found to score lower on Neuroticism than non-gifted adolescents [20,35]. Openness to experience is linked to over excitabilities (OE's) [34], although over excitabilities are part of a theoretical model (TPD) and cannot be used as single constructs [23].

We examined personality development in grades 8 and 10 (Table 1). This age range was of interest because several recent studies have shown the biological and psychological transitions from childhood into adolescence to be accompanied by temporary dips in specific aspects of personality (i.e., the disruption hypothesis). Several research has found the mean levels of Openness to experience, Conscientiousness and Agreeableness to decrease during the transition from late childhood into early adolescence but then increase rapidly from late adolescence into early adulthood and continue to increase - but more gradually — from early adulthood into and throughout middle age. Extraversion was also found to drop in adolescence while Neuroticism increased in females but not males [29, 32, 19]. It's thus possible that the personality characteristics of above-average intelligence and gifted adolescents are not particularly stable, just as for other adolescents.

Table 1. Participant Numbers for Completion of Personality Testing in not only Grade 8 but also Grade 10: Neuroticism (N), Extraversion (E), Imagination (I) (i.e., Openness to Experience), Benevolence (B), Conscientiousness (C).

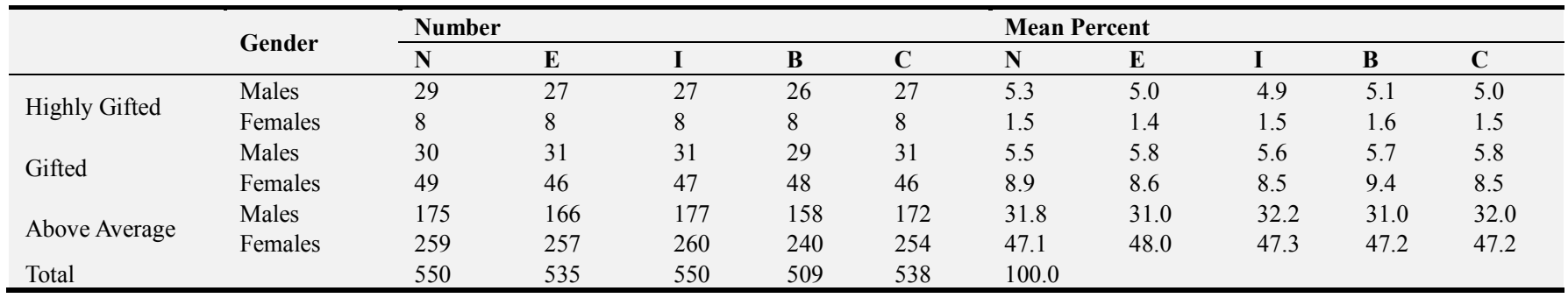

Finally, we investigated the Strengths and Difficulties, as experienced by the adolescents in this study, in order to give an estimation of their mental health (Table 2). Research found comparable scores between gifted and non-gifted adolescents on subtests from the Strengths and Difficulties Questionnaire (SDQ) with one exception. The gifted showed a tendency to be slightly more inattentive/hyperactive than the non-gifted adolescents [12]. We believe that this can be explained by the mismatch in the educational curriculum for the gifted student and thus a possible finding in the present study as well.

Table 2. Participant Numbers for Completion of Strengths and Difficulties Testing in not only Grade 8 but also Grade 10.

\begin{tabular}{llll}
\hline & Gender & Number & Percent \\
\hline Highly gifted & Male & 16 & 5.0 \\
& Female & 4 & 1.2 \\
Gifted & Male & 21 & 6.5 \\
& Female & 28 & 8.7 \\
Above average intelligent & Male & 99 & 30.8 \\
& Female & 153 & 47.7 \\
Total & & 321 & 100.0 \\
\hline
\end{tabular}

Drawing on the above, we explored the following three research questions.
1) Do highly gifted and gifted adolescents differ from above-average intelligent adolescents in their "Little Five" personality traits (i.e., (Openness to Experience) Imagination (Creativity, Intellect, Curiosity); Conscientiousness (Concentration, Perseverance, Orderliness, Achievement striving); Extraversion (Energy, Expressiveness, Optimism, Shyness), (Agreeableness) Benevolence (Altruism, Dominance, Egocentrism, Compliance, Irritability), and Neuroticism (Anxiety, Self-confidence)? -We use the term "Little Five" as these traits are comparable to the Big Five (OCEAN) but extended to children and adolescents. Also two traits are worded differently due to minor differences: Openness to Experience (Imagination) Agreeableness (Benevolence) -1a) Do highly gifted and gifted adolescents score significantly higher on the trait Openness to Experience compared to adolescents with above average intelligence?

2) Do the personality traits of the highly gifted, gifted compared to adolescents with above-average intelligence change in a different manner over time (i.e., are they the same or different in grade 8 versus grade 10)? 
3) Do highly gifted, gifted, and adolescents with above-average intelligence differ in their mental health Strengths and Difficulties (total problems, emotional problems, behavioral problems, hyperactivity, and peer problems versus positive and prosocial behavior)?

We expect gifted and especially highly gifted adolescents to be more open to Experience than adolescents with above-average intelligence. We expected, in line with other research, to find highly gifted and gifted adolescents to show lower Neuroticism than adolescents with above-average intelligence. We did not expect other differences to occur.

\section{Method}

\subsection{Participants}

For purposes of the present longitudinal research, 846 students in grade 8 (11-15 years, mean of 13.58 years) were initially recruited with a sample of 561 students resulting in grade 10 (13-17 years, mean of 15.91 years). Due to the occurrence of a flu epidemic during the test days in grade 10 , 285 participants were not able to participate. All eighth graders from six schools were invited to participate in the present research with no selection from gifted programs or on the basis of teacher recommendations. All participants were approached by their schools. Six schools located in the region around the city of 's-Hertogenbosch in the south of the Netherlands participated in the study. There was a seventh school with a high percentage of immigrant pupils. The other six schools were comparable with a low percentage of immigrant pupils. To keep the sample internally consistent, the school with the high percentage was excluded from participation. The schools provide a rich and varied selection of educational programs encompassing the 10 levels of education common in the Netherlands at the time. ${ }^{1}$ Three of the schools offered only VWO gymnasium, which includes the subject of Latin and Greek. The other three schools offered several levels of education: VMBO/HAVO; HAVO and $H A V O$ bilingual; $V W O$ athenaeum (no Latin and Greek) and $V W O$ athenaeum bilingual. Students in the lower levels of education $(V M B O)$ were removed from the study when the questions and responding required for participation in the present study were judged by teachers to be too difficult for such students.

Two years later, during grade 10 , the participants in our study had entered five levels of education: VMBO (average), HAVO, $H A V O$ bilingual, VWO athenaeum, and VWO gymnasium.

\subsection{Procedure and Measurement Instruments}

The adolescents and their parents were informed about the aims of the research project: to gain insight into personality

\footnotetext{
1 Dutch secondary education has three core streams: one to prepare for vocational training ( $V M B O$ taking 4 years.); one to prepare for study at a university of applied science ( $H A V O$ taking 5 years); and one to prepare for university study ( $V W O$ taking 6 years). Students start secondary school around the age 12. Often an orientation year (Grade 7 and sometimes also grade 8) is possible. Bilingual schools (Dutch-English) are also a possibility. VWO is divided into athenaeum and gymnasium with latter requiring the study of Latin, Greek, and ancient cultures.
}

and cognitive, social, and emotional functioning. After approval by the student and written authorization by a parent, the students were then given verbal instructions in the classroom and asked to independently complete a nonverbal, abstract, cognitive functioning test and ten questionnaires. For purposes of the present study, we used two capacity tests and two self-report questionnaire to assess personality factors and strengths and difficulties in grades 8 and 10 .

\subsubsection{Hierarchical Personality Inventory for Children (HiPIC) (Mervielde \& de Fruyt 1999)}

The Hierarchical Personality Inventory for Children (HiPIC) is an inventory for use by parents and teachers to report on a child but also intended for use as a self-report tool with adolescents. On the basis of responding to 144 items, the HiPIC assesses 5 higher-order traits with 18 lower-order facets of personality (i.e.,: Openness to Experience or Imagination: Creativity, Intellect and Curiosity; Conscientiousness: Concentration, Perseverance, Orderliness and Achievement striving; Extraversion: Energy, Expressiveness, Optimism and Shyness (-); Agreeableness or Benevolence: Altruism, Dominance (-), Egocentrism (-), Compliance and Irritability (-) and Neuroticism: Anxiety (-) and Self-confidence) [9]. Respondents rate each item along a five-point Likert scale. Strong support for the structural validity, interrater agreement, internal consistency, and temporal stability of the HIPIC has been found [10]. For Dutch mothers, the inter-rater reliability has been shown to lie between .83 and .90 (Cronbach's $\alpha$ ).

\subsubsection{Strengths and Difficulties Questionnaire (SDQ; Goodman, 1997)}

The Strengths and Difficulties Questionnaire $(S D Q)$ is one of the most frequently used screening instruments for the identification of child and adolescent mental health problems across the world. The instrument subsumes five scales with five items each: emotional symptoms, conduct problems, hyperactivity/inattention, peer relationship problems, and prosocial behavior. Each item can be answered with "not true" (0), "somewhat true" (1), or "certainly true" (2). The four problem scales can generate a total difficulties score with a range of 0 to 40 . Concurrent validity has been demonstrated with similar questionnaires including the Child Behavior Checklist (CBCL) and the Rutters Questionnaire [15, 16]. There are three versions of the SDQ: self-report, parent, and teacher. We used the self-report version. The internal consistency of the self-report version has been shown to be satisfactory in several studies [28].

\subsection{Data Analysis}

As cognitive capacity may influence the responding of participants, multiple analyses of variance (MANOVAs with the statistic Wilks' Lambda) were conducted to determine the effects of these independent variables (i.e., cognitive capacity, gender) on the dependent variables of interest in the current study (i.e., the personality traits and strengths \& difficulties). To guard against the occurrence of Type I errors (i.e., finding false positives) [30], the alpha for establishing statistical 
significance was set at .01 . To avoid arbitrary cut-off points for grouping by intelligence, we examined the average posterior probability (AvePPj) with the Bayes factor. The factor was for almost all of the questionnaires used in this study much larger than the required of 0.70 .

\section{Results}

In this study, we found highly gifted, gifted adolescents to differ significantly on two personality traits, namely Openness to Experience and Conscientiousness, from cognitively above average adolescents. In line with our expectations adolescents in this study report comparable emotional stability, agreeableness, difficulties and positive or pro-social behavior.

\subsection{Personality}

The findings on personality in this study shows the grouping variable of "cognitive capacity" to account for a large portion of the variance that is found using the Wilk's Lambda test. No significant interactions were found between cognitive capacity and gender, $\Lambda=.871, \mathrm{~F}(72,766)=.764$, $\mathrm{p}$ $<.925, \eta p^{2} .067$. Homogeneity of variance was found; the variances were equal across the highly gifted, gifted, and cognitively above average adolescents according to the Levene's Test. We therefore set our significance level to $<.05$, except for Benevolence $(\mathrm{p}<.006)$ and the lower-trait factors Perseverance (in grade $8, \mathrm{p}<.005$ ) and Perseverance (in grade $10, \mathrm{p}<.006)$, Irritability $(\mathrm{p}<.019)$ and Compliance $(\mathrm{p}<.008)$ for these facets, the significance level was set to $<.01$.

\subsubsection{Imagination}

Openness to Experience or Imagination is a personality trait in the present study to vary depending on level of Cognitive Capacity and thus show a main effect of Cognitive Capacity, $\Lambda=.943, F(12,1078)=2.651, p<.002, \eta_{\mathrm{p}}{ }^{2} .029$ (Table 3). Neither a main effect of Gender nor an interaction of Gender with Cognitive Capacity was found. Imagination $(p<.001)$ and the lower-order facets Intellect $(p<.000)$ and Curiosity facet $(p<.001)$ - all in in grade $10-$ accounted for the observed variance in Imagination. Creativity did not. A small effect for the Curiosity facet of personality in grade 8 was also found ( $p<.048)$. Tukey (post-hoc) analyses showed the gifted adolescents in grade 8 to be slightly more curious than the adolescents with above-average intelligence in grade 8 ( $p$ $<.035$ ). There were no significant differences depending on Cognitive Capacity for the Creativity facet of personality.

Table 3. Openness to Experience/Imagination in highly gifted, gifted and above average intelligent adolescents in grades 8 and 10 .

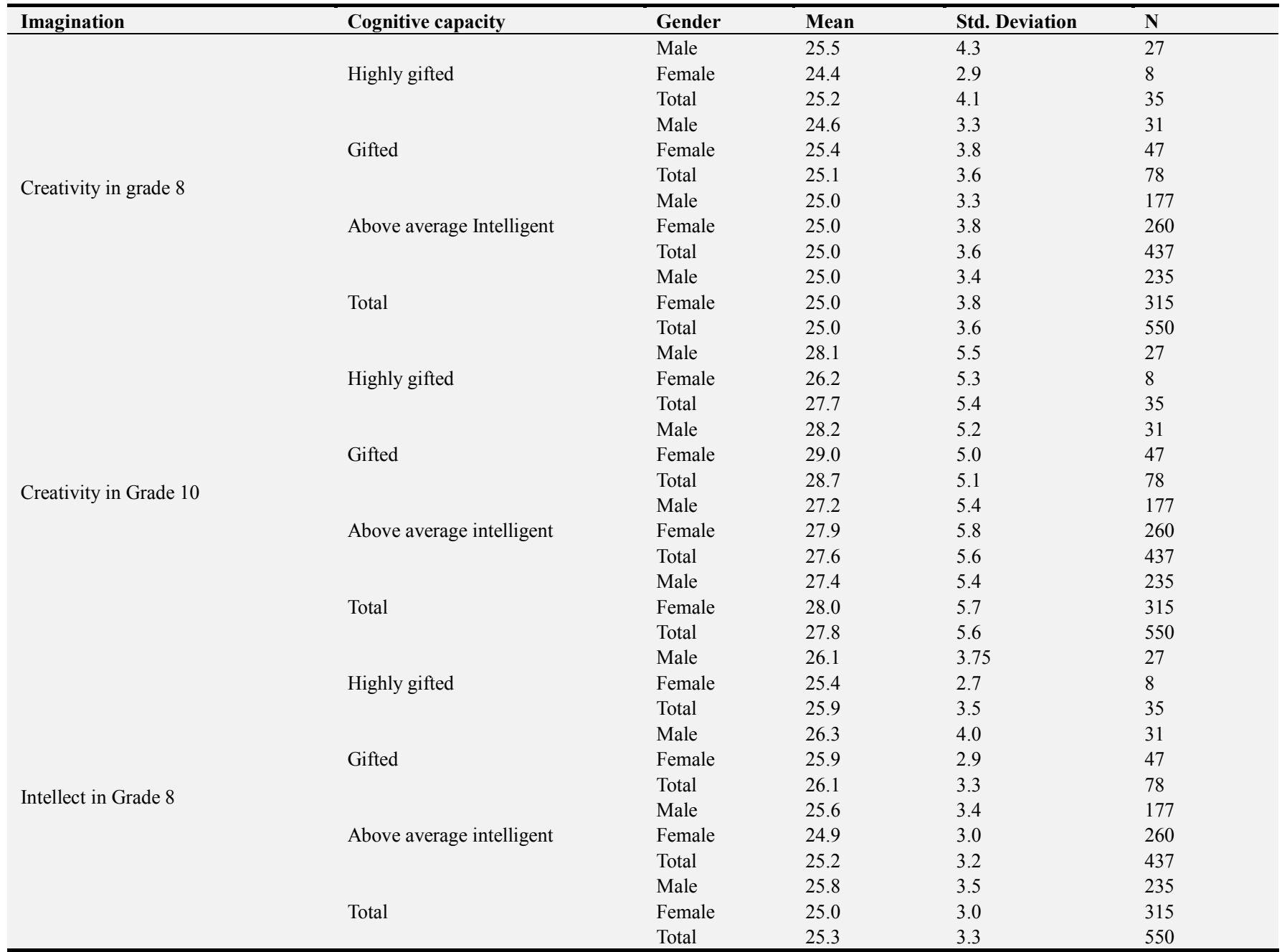




\begin{tabular}{|c|c|c|c|c|c|}
\hline Imagination & Cognitive capacity & Gender & Mean & Std. Deviation & $\mathbf{N}$ \\
\hline \multirow{13}{*}{ Intellect in Grade 10} & \multirow{3}{*}{ Highly gifted } & Male & 31.3 & 4.8 & 27 \\
\hline & & Female & 29.3 & 3.4 & 8 \\
\hline & & Total & 30.9 & 4.5 & 35 \\
\hline & \multirow{3}{*}{ Gifted } & Male & 30.1 & 4.8 & 31 \\
\hline & & Female & 29.8 & 3.3 & 47 \\
\hline & & Total & 29.9 & 4.0 & 78 \\
\hline & \multirow{3}{*}{ Above average intelligent } & Male & 28.9 & 4.1 & 177 \\
\hline & & Female & 27.2 & 4.2 & 260 \\
\hline & & Total & 27.9 & 4.3 & 437 \\
\hline & \multirow{4}{*}{ Total } & Male & 29.4 & 4.3 & 235 \\
\hline & & Female & 27.7 & 4.2 & 315 \\
\hline & & Total & 28.4 & 4.3 & 550 \\
\hline & & Male & 28.4 & 5.9 & 27 \\
\hline \multirow{10}{*}{ Curiosity in Grade 8} & \multirow[t]{2}{*}{ Highly gifted } & Female & 26.8 & 4.5 & 8 \\
\hline & & Total & 28.1 & 5.6 & 35 \\
\hline & \multirow{3}{*}{ Gifted } & Male & 28.9 & 4.6 & 31 \\
\hline & & Female & 28.4 & 4.3 & 47 \\
\hline & & Total & 28.6 & 4.4 & 78 \\
\hline & \multirow{4}{*}{ Above average intelligent } & Male & 27.5 & 4.4 & 177 \\
\hline & & Female & 27.1 & 3.9 & 260 \\
\hline & & Total & 27.3 & 4.1 & 437 \\
\hline & & Male & 27.8 & 4.6 & 235 \\
\hline & \multirow[t]{3}{*}{ Total } & Female & 27.3 & 4.0 & 315 \\
\hline \multirow{14}{*}{ Curiosity in Grade 10} & & Total & 27.5 & 4.3 & 550 \\
\hline & & Male & 30.4 & 3.7 & 27 \\
\hline & \multirow[t]{3}{*}{ Highly gifted } & Female & 29.4 & 3.2 & 8 \\
\hline & & Total & 30.2 & 3.6 & 35 \\
\hline & & Male & 29.5 & 3.9 & 31 \\
\hline & \multirow[t]{2}{*}{ Gifted } & Female & 29.4 & 3.7 & 47 \\
\hline & & Total & 29.4 & 3.7 & 78 \\
\hline & \multirow{3}{*}{ Above average intelligent } & Male & 27.6 & 4.8 & 177 \\
\hline & & Female & 27.9 & 4.2 & 260 \\
\hline & & Total & 27.8 & 4.4 & 437 \\
\hline & \multirow{4}{*}{ Total } & Male & 28.1 & 4.7 & 235 \\
\hline & & Female & 28.2 & 4.1 & 315 \\
\hline & & Total & 28.2 & 4.4 & 550 \\
\hline & & Male & 80.0 & 11.6 & 27 \\
\hline \multirow{10}{*}{ Imagination in Grade 8} & Highly Gifted & Female & 76.5 & 7.8 & 8 \\
\hline & & Total & 79.2 & 10.9 & 35 \\
\hline & & Male & 79.8 & 11.0 & 31 \\
\hline & Gifted & Female & 79.7 & 8.6 & 47 \\
\hline & & Total & 79.8 & 9.5 & 78 \\
\hline & & Male & 78.1 & 9.0 & 177 \\
\hline & Above Average Intelligent & Female & 76.9 & 8.9 & 260 \\
\hline & & Total & 77.4 & 8.9 & 437 \\
\hline & & Male & 78.6 & 9.6 & 235 \\
\hline & Total & Female & 77.3 & 8.8 & 315 \\
\hline & & Total & 77.9 & 9.2 & 550 \\
\hline & & Male & 89.9 & 9.6 & 27 \\
\hline & Highly Gifted & Female & 84.9 & 5.2 & 8 \\
\hline & & Total & 88.7 & 9.0 & 35 \\
\hline & & Male & 87.7 & 11.0 & 31 \\
\hline & Gifted & Female & 88.3 & 8.2 & 47 \\
\hline Impringtion in $C$ rade 1 & & Total & 881 & 9.3 & 78 \\
\hline Imagination in Grade 10 & & Male & 83.7 & 11.4 & 177 \\
\hline & Above average intelligent & Female & 83.0 & 10.7 & 260 \\
\hline & & Total & 83.3 & 11.0 & 437 \\
\hline & & Male & 84.9 & 11.3 & 235 \\
\hline & Total & Female & 83.9 & 10.4 & 315 \\
\hline & & Total & 84.3 & 10.8 & 550 \\
\hline
\end{tabular}

In grade 10, as already mentioned and to be seen in Figure 1, the gifted and the highly gifted differed significantly on the higher-order trait Imagination from the adolescents with above-average intelligence $(p<.011)$. 


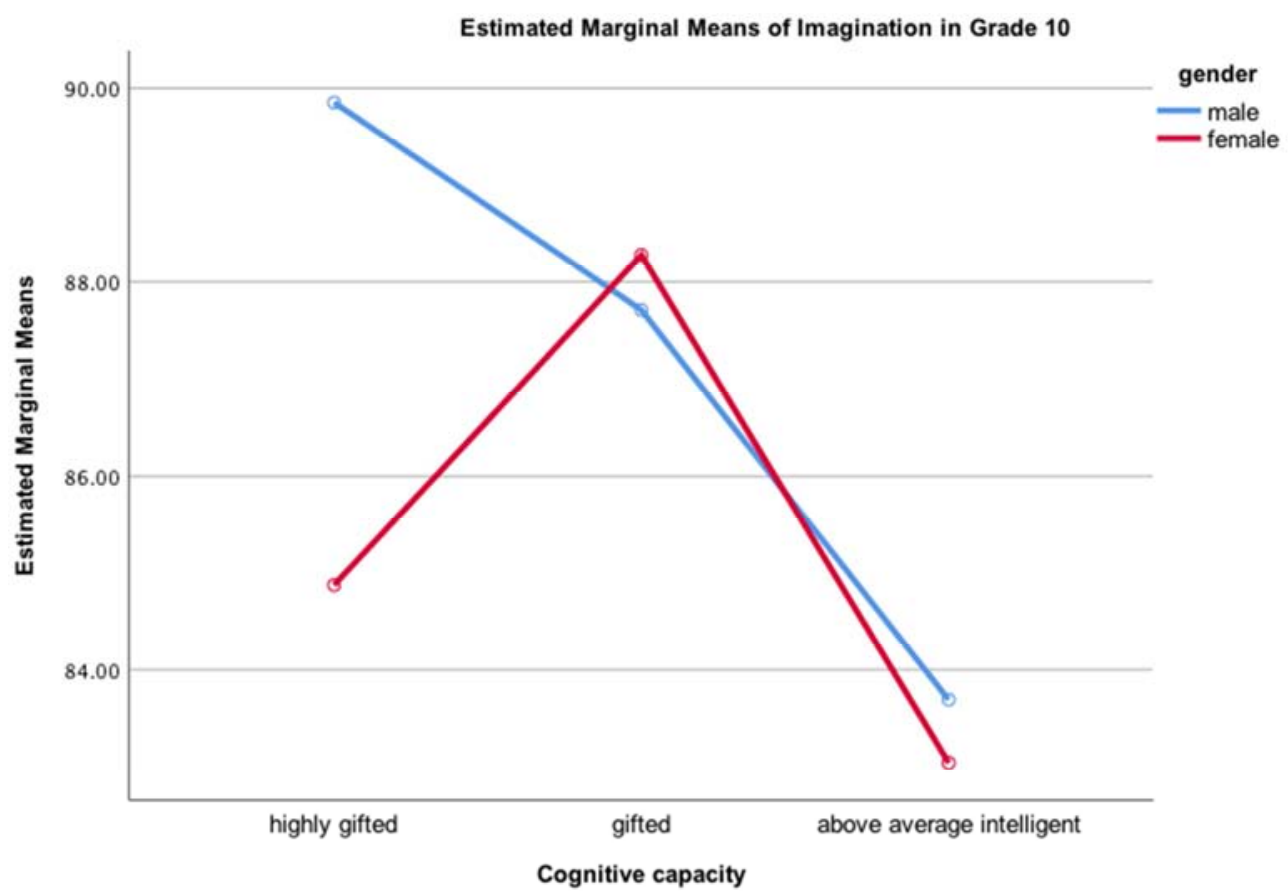

Figure 1. This figure depicts the means in highly gifted, gifted and above average intelligent adolescents in Grade 10 for the trait Openness to Experience/Imagination.

And in grade 10, both the gifted and highly gifted adolescents differed significantly from those for the adolescents with above-average intelligence $(p<.000)$ on the lower-order Intellect facet of personality. Also, in grade 10, the gifted and the highly gifted reported a significantly greater
Intellect, i.e., understanding of how things work, ability to express themselves easily, and opinion that they make a sensible impression on others when compared to the adolescents with above-average intelligence (Figure 2).

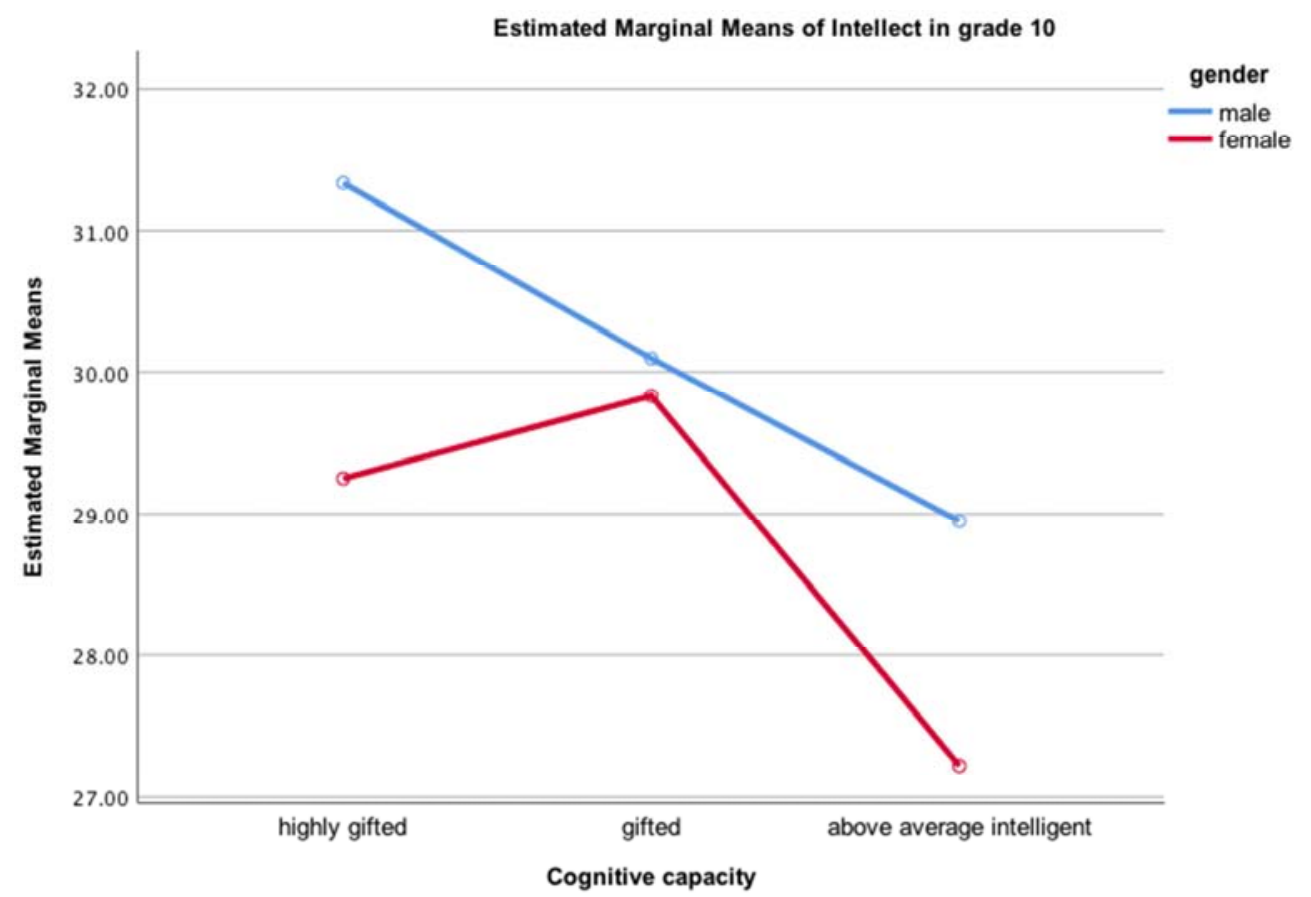

Figure 2. This figure depicts the means in highly gifted, gifted and above average intelligent adolescents in Grade 10 for the low-order facet of personality Intellect of the trait Openness to Experience/Imagination.

And, in grade 10, the gifted and highly gifted adolescents also reported being more knowledgeable, eager to learn, interested in actively investigating things, having broader interests, and having more hobbies than the adolescents with above-average intelligence $(p<.005)$. All characteristics of the Curiosity facet of personality (Figure 3 ). 


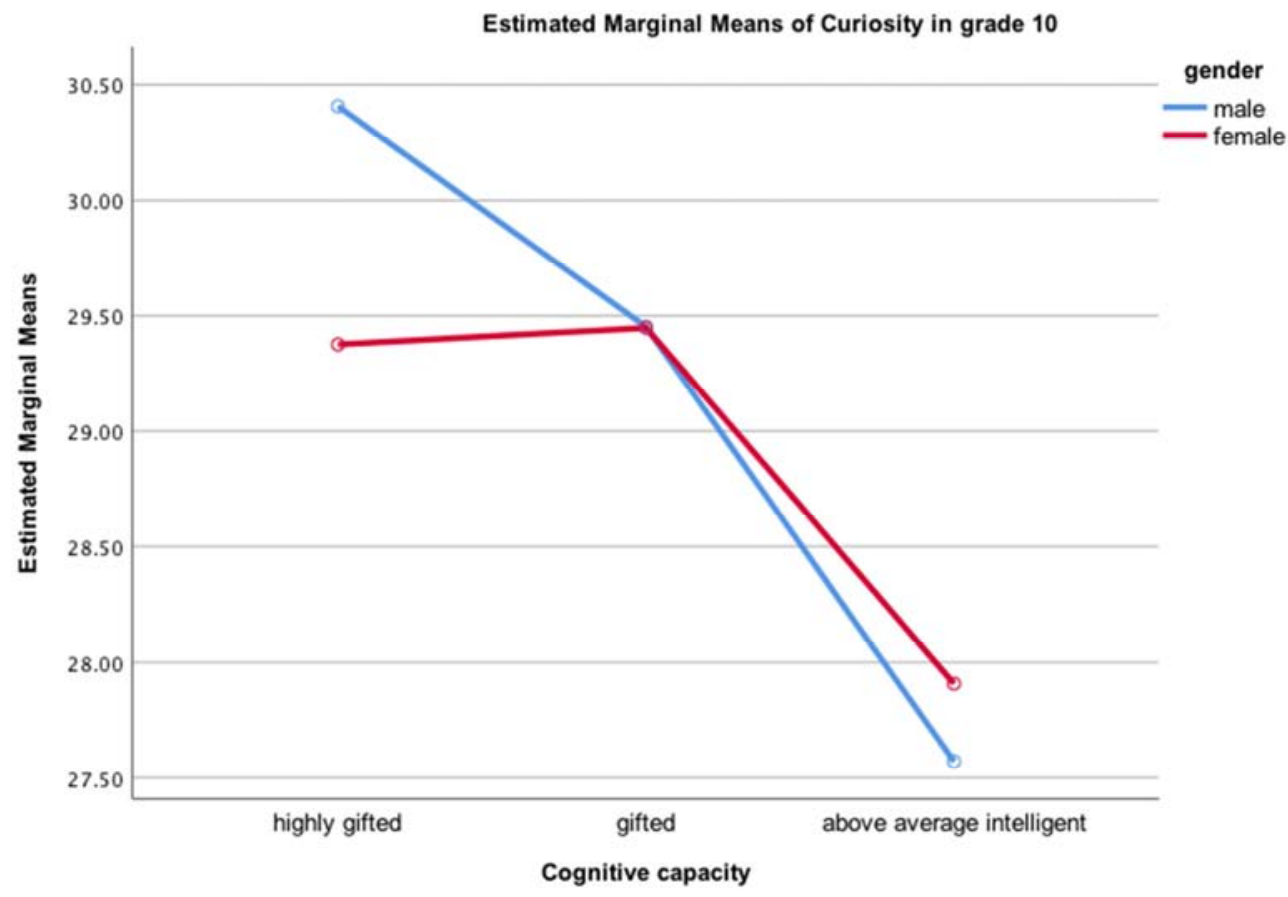

Figure 3. This figure depicts the means in highly gifted, gifted and above average intelligent adolescents in Grade 10 for the low-order facet of personality Curiosity of the trait Openness to Experience/Imagination.

\subsubsection{Conscientiousness}

Main effect of Cognitive Capacity $(\Lambda=.948, F(16,1050)$ $\left.=1.763, p<.031, \eta_{\mathrm{p}}{ }^{2} .026\right)$ on the higher order personality trait of Conscientiousness was found. The variance in the influence of Cognitive Capacity is explained by the lower-order Concentration facet of personality $(p<.005)$ and the higher order Conscientiousness trait $(p<.008)$, both in grade 10 . In grade 10 , all of the gifted adolescents scored consistently higher on both Concentration $(p<.004)$ and Conscientiousness $(p<.036)$ than all of the adolescents with above-average intelligence in the same grade. As depicted in Figure 4, it is seen that the male highly gifted and all adolescents with above-average intelligence continue to show average levels of Concentration while the other (i.e., highly gifted females and gifted adolescents) now report above average levels.

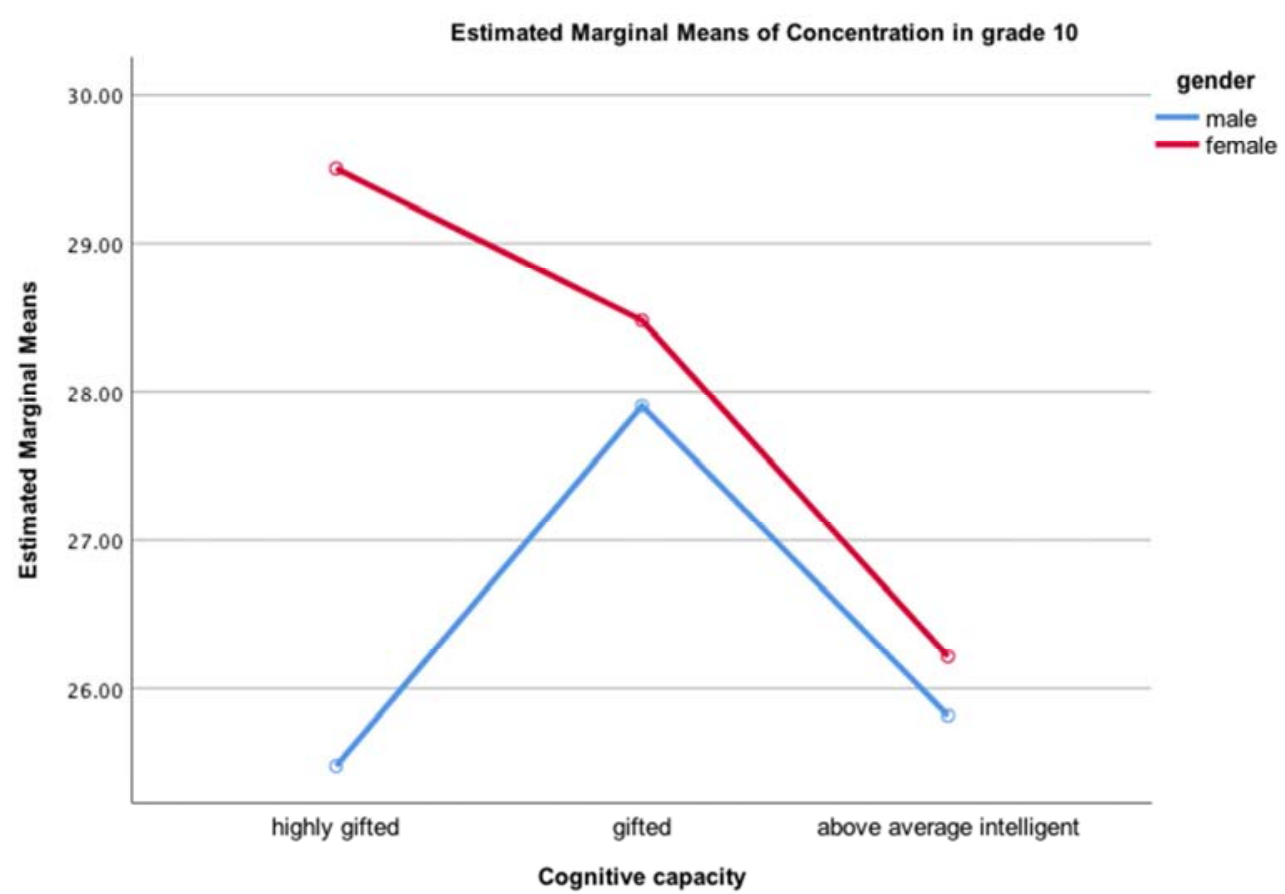

Figure 4. This figure depicts the means in highly gifted, gifted and above average intelligent adolescents in Grade 10 for the low-order facet of personality Concentration of the trait Conscientiousness. 


\subsubsection{Extraversion, Benevolence and Neuroticism}

For the higher-order personality trait of Extraversion, (Agreeableness) Benevolence and Neuroticism we found no main effect of Cognitive Capacity and no interaction between Gender and Cognitive Capacity.

\subsubsection{Changes in Personality in Two Years}

Repeated measure MANOVA showed significant difference in the Cognitive Capacity groups over time (i.e., between grades 8 and 10) for the Agreeableness or Benevolence personality trait, $\Lambda=.986, F(2,506)=3.493, p<.031, \eta_{\mathrm{p}}^{2} .014$. This was explained by the growth over time for the gifted adolescents $(p=.012)$ and adolescents with above-average intelligence $(p=.010)$ relative to the highly gifted adolescents.

Larger change over time and greater amount of variability between the Cognitive Capacity groups was found for the (Openness to Experience) Imagination personality trait, $\Lambda$ $=.985, F(2,547)=4.220, p<.015, \eta_{\mathrm{p}}{ }^{2} .015$. As can be seen in Figure 5, the Imagination scores for both the highly gifted adolescents and gifted adolescents increased significantly more from group 8 to group 10 when compared to the Imagination scores for the adolescents with above-average intelligence $(p=.003)$.

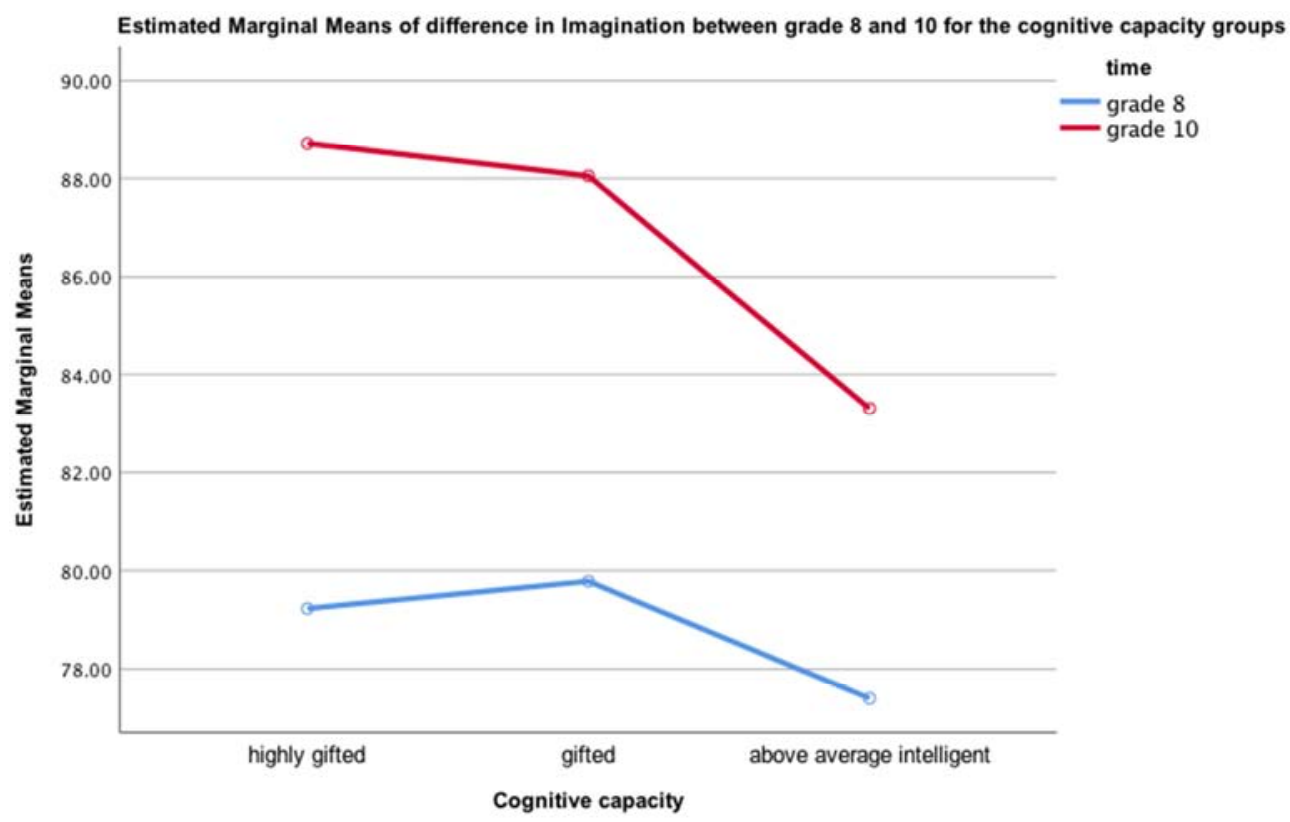

Figure 5. This figure depicts the means of the difference over time between Grade 8 and 10 for the highly gifted, gifted and above average intelligent adolescents for the trait Openness to Experience/Imagination.

\subsection{Strengths and Difficulties}

Turning to Strengths and Difficulties, there was no main effect of Cognitive Capacity on emotional symptoms, conduct problems, hyperactivity-inattention, peer problems, the total difficulty scale, or on prosocial behavior. The Wilk's Lambda test for Strengths and Difficulties was $\Lambda=.949, F(20,612)$ $=.817, p<.694 \eta_{\mathrm{p}}^{2} .026$.

\section{Discussion}

In line with what we expected on personality (research question 1), the gifted and highly gifted adolescents in our study scored just as high on the personality traits of Extraversion and Benevolence (Agreeableness) as the adolescents with above-average intelligence. Contrary to what was in line with other research expected, they scored comparable on Neuroticism with the adolescents with above-average intelligence. In keeping with what we expected, the self-reported ratings for Openness to Experience (or Imagination) by the gifted and especially the highly gifted adolescents were significantly higher than those of the adolescents with above-average intelligence (research question 1a). In contrary to what we expected the highly gifted did not differ significantly in their Openness to Experience compared to the gifted adolescents (research question 1a). Unexpected, highly gifted females and gifted adolescents did score significantly higher on the lower order facet Concentration, also in grade 10 .

And as we expected, the development over time (grade 8 to 10) of most personality traits in the highly gifted, gifted compared to adolescents with above-average intelligence was comparable (research question 2). However, the gifted and above average intelligent adolescents grow and develop more in Agreeableness (or Benevolence) than the highly gifted adolescents. And, although the gifted adolescents in grade 8 were only slightly more curious than the above average intelligent adolescents, a significant growth in the personality of the highly gifted and gifted adolescents took place between grade 8 and 10 in the trait Openness to Experience (or Imagination). As can be seen in Figure 5, the Imagination scores for both the highly gifted adolescents and gifted adolescents increased significantly more from group 8 to group 10 when compared to the Imagination scores for the 
adolescents with above-average intelligence $(p=.003)$.

And finally, the highly gifted and gifted adolescents were comparable mentally strong to above-average intelligence in their Strengths and Difficulties (total problems, emotional problems, behavioral problems, hyperactivity, and peer problems versus positive and prosocial behavior) (research question 3).

In attempts to understand why gifted adolescents behave as they behave, implicit theories of the personality (e.g., gifted adolescents are less agreeable, are hyperactive, less emotionally stable) have been applied but led to greater misunderstanding than understanding. The aim of the present study was therefore to address the question using the well-documented Five Factor Model of personality as well as investigating the HDP definition.

In line with the results of other research, Dutch highly gifted and gifted adolescents report: knowledge of how things work, an ability to express themselves easily, making a sensible impression, considering themselves knowledgeable, show an eagerness to learn, a desire to actively investigate things, a broad range of interests, and many hobbies (e.g. "many gifted adolescents actually like learning, love working hard in order to accomplish cognitive tasks, and wish to have more and more difficult subjects they can absorb themselves in" ([5], p. 113). The scores of the highly gifted and gifted adolescents on the cognitive capacity tests as well their significantly higher scores on the lower-order personality facet Intellect match with component 1a of the High Developmental Potential (HDP) definition: High sensory perception allowing an unusually large amount of information to be perceived and processed in depth.

The highly gifted and gifted adolescents in our study score significantly higher on the personality trait Openness to Experience (or Imagination) and on the lower-order facets Intellect and Curiosity, than the adolescents with above-average intelligence, especially in grade 10 . These findings confirm component 2 of the HDP definition. The disruption hypothesis may explain for the fall in Openness to Experience in grade 8 .

On the lower-order facet Concentration, the highly gifted females and gifted adolescents in grade 10, scored significantly higher. In other words, they can keep busy with something for an extended period of time and that they usually finish the tasks that they have started on.

Finally, no evidence was found for the negative stereotype that gifted adolescents tend to be emotionally unstable and less agreeable than other adolescents.

Concluding, what really drives gifted and highly gifted individuals is Openness to Experience and especially, Intellect and Curiosity.

The present study has several strengths. In order to obtain a random sample, we invited all of the eighth graders from six schools to participate in our research and therefore did not recruit from only gifted programs or on the basis of teacher recommendations. We also compared gifted and highly gifted adolescents to adolescents with above-average intelligence, which provided a powerful comparison group compared to average intelligent adolescents. The study was longitudinal, with 560 students responding in both grades 8 and 10. In-depth interviews are also currently being conducted with the 6 most highly gifted adolescents from our study who are now young adults (to be reported on later). Another major strength is the present research is that it is based upon the widely and clearly documented Five-Factor Model (FFM) of personality.

A possible limitation on the present study is its reliance on self-report data. Self-reporting is widely assumed to be susceptible to social desirability bias or, in other words, an inclination to respond in a socially desirable manner [26]. Self-report and actual behavior may thus differ at times. Especially when topic is particularly sensitive, potentially incriminating, or possibly embarrassing, self-reporting may be biased. In adolescence and particularly during group testing, a marked inclination to respond as the rest, be like the rest, fit in with peers, and thus be viewed as normal may manifest itself. We tried to avoid such bias by placing tables and chairs at a distance during all testing and thus preventing the possibility of respondents seeing the answers of others. Adolescents, in particular, may distrust the adult who will be reading and judging their responding and they may therefore inaccurately report the presence or severity of symptoms [26]. Nevertheless, adolescents are generally considered to be the best reporters of their symptoms, particularly when internalizing problems or trauma are of concern [25]. Researchers have also indeed found that self-report data is accurate when respondents can clearly understand the questions asked and when there is a strong sense of anonymity and therefore little fear of reprisal. We therefore eliminated the data for the adolescents with average intelligence after their teachers reported that these students did not understand the questions well enough. We also explicitly told the respondents that their data would be treated anonymously and with utmost care. And we reassured the respondents that there were no "right" or "wrong" answers to the questions being asked. A final possible limitation on the present study is that the factors obtained using the SDQ are not unidimensional [17, $21,28]$. It is therefore recommended that the total score be used in the future rather than individual subscale scores.

\section{Conclusion}

When studying the self-reports of behavior from individuals with a high developmental potential, we found highly gifted and gifted adolescents to differ significantly from adolescents with above-average intelligence on the personality trait of Openness to Experience. This personality trait also increased significantly more from grade 8 to grade 10 for both the highly gifted adolescents and gifted adolescents compared to the adolescents with above-average intelligence. In grade 10, all of the gifted adolescents scored consistently higher on the personality trait of Conscientiousness and particularly the lower order Concentration facet of Conscientiousness than the adolescents with above-average intelligence in the same grade. The highly gifted females also showed above average levels of Concentration while the highly 
gifted males showed average levels. For the other three personality traits of Extraversion, (Agreeableness) Benevolence, and Neuroticism, the adolescents in our study did not differ from each other. In line with our expectations, the adolescents we studied reported comparable levels of emotional stability, agreeableness, difficulties, and positive or pro-social behavior on average. Openness to Experience with the lower order Intellect and Curiosity facets clearly characterized the highly gifted and gifted adolescents in our study than the adolescents with above-average intelligence. This finding supports element 2 of the definition of a high developmental potential, namely Openness to Experience, which can be measured using a personality test.

\section{Recommendation}

Openings from the environment and opportunities are needed for gifted children to maintain and support the defining personality facet of Curiosity. This should be done from a very early age.

\section{References}

[1] Amthauer, R., Brocke, B., Liepmann, D., \& Beauducel, A. (2001). Intelligence Structure Test 2000 (revised).

[2] Baudson, T. G., \& Preckel, F. (2013). Teachers' implicit personality theories about the gifted: An experimental approach. School psychology quarterly, 28 (1), 37.

[3] Conley, J. J. (1984). Longitudinal consistency of adult personality: self-reported psychological characteristics across 45 years. Journal of Personality and Social Psychology, 47 (6), 1325.

[4] Costa Jr, P. T., \& McCrae, R. R. (1992). Four ways five factors are basic. Personality and individual differences, 13 (6), 653-665.

[5] David, H. (2018). Problems and challenges of the gifted adolescent: School-related problems of the gifted adolescent. Journal of Interdisciplinary Sciences, 2 (2), 113-131.

[6] De Clercq, B., \& De Fruyt, F. (2003). Personality disorder symptoms in adolescence: A five-factor model perspective. Journal of Personality Disorders, 17 (4), 269-292.

[7] De Clercq, B., De Fruyt, F., \& Van Leeuwen, K. (2004). A "little five" lexically based perspective on personality disorder symptoms in adolescence. Journal of Personality Disorders, 18 (5), 479-499.

[8] De Clercq, B., De Fruyt, F., \& Widiger, T. A. (2009). Integrating a developmental perspective in dimensional models of personality disorders. Clinical Psychology Review, 29 (2), 154-162.

[9] De Clercq, B., \& De Fruyt, F. (2012). A five-factor model framework for understanding childhood personality disorder antecedents. Journal of Personality, 80 (6), 1533-1563.

[10] De Fruyt, F., Bartels, M., Van Leeuwen, K. G., De Clercq, B., Decuyper, M., \& Mervielde, I. (2006). Five types of personality continuity in childhood and adolescence. Journal of Personality and Social Psychology, 91 (3), 538.

[11] Digman, J. M. (1996). The curious history of the five-factor model. In J. S. Wiggins (ed.) The Five-Factor Model of
Personality: Theoretical Perspectives (pp. 21-50). New York, NY: Guilford.

[12] Eren, F., Çete, A. Ö., Avcil, S., \& Baykara, B. (2018). Emotional and behavioral characteristics of gifted children and their families. Archives of Neuropsychiatry, 55 (2), 105.

[13] Erikson, E. H. (1968). Identity: youth and crisis. Oxford, England: Norton.

[14] Goldberg, L. R. (1993). The structure of phenotypic personality traits. American psychologist, 48 (1), 26.

[15] Goodman, R. (1997). The Strengths and Difficulties Questionnaire: a research note. Journal of child psychology and psychiatry, 38 (5), 581-586.

[16] Goodman, R. (1999). The extended version of the Strengths and Difficulties Questionnaire as a guide to child psychiatric caseness and consequent burden. Journal of child psychology and psychiatry, 40 (5), 791-799.

[17] Goodman, A., Lamping, D. L., \& Ploubidis, G. B. (2010). When to use broader internalizing and externalizing subscales instead of the hypothesized five subscales on the Strengths and Difficulties Questionnaire (SDQ): data from British parents, teachers and children. Journal of abnormal child psychology, 38 (8), 1179-1191.

[18] Hendriks, A. A. J., Hofstee, W. K. B., \& De Raad, B. (1999). Handleiding bij de Five-Factor Personality Inventory (FFPI) [The Five-Factor Personality Inventory: Professional manual]. Lisse: Swets.

[19] Klimstra, T. A., Bleidorn, W., Asendorpf, J. B., Van Aken, M. A., \& Denissen, J. J. (2013). Correlated change of Big Five personality traits across the lifespan: A search for determinants. Journal of Research in Personality, 47 (6), 768-777.

[20] McCrae, R. R., Costa Jr, P. T., Terracciano, A., Parker, W. D., Mills, C. J., De Fruyt, F., \& Mervielde, I. (2002). Personality trait development from age 12 to age 18: Longitudinal, cross-sectional and cross-cultural analyses. Journal of personality and social psychology, 83 (6), 1456.

[21] Mellor, D., \& Stokes, M. (2007). The factor structure of the Strengths and Difficulties Questionnaire. European Journal of Psychological Assessment, 23 (2), 105-112.

[22] Mendaglio, S. (Ed.). (2008). Dabrowski's theory of positive disintegration. Scottsdale, ZA: Great Potential Press, Inc.

[23] Mendaglio, S. (2012). Overexcitabilities and giftedness research: A call for a paradigm shift. Journal for the Education of the Gifted, 35 (3), 207-219.

[24] Mervielde, I., De Fruyt, F., \& De Clercq, B. (2009). HiPIC: Hiërarchische Persoonlijkheidsvragenlijst voor Kinderen [HiPIC: Hierarchical Personality Inventory for Children]. Hogrefe.

[25] Nader, K. (2008). How children and adolescents are affected by trauma. The history of assessing trauma in youths. Understanding and assessing trauma in children and adolescents: measures, methods, and youth in context.

[26] Nader, K. (2011). Trauma in children and adolescents: Issues related to age and complex traumatic reactions. Journal of Child \& Adolescent Trauma, 4 (3), 161-180.

[27] Raven, J. C., \& John Hugh Court. (1998). Raven's progressive matrices and vocabulary scales. Oxford, England: Oxford psychologists Press. 
[28] Richter, J., Sagatun, Å., Heyerdahl, S., Oppedal, B., \& Røysamb, E. (2011). The strengths and difficulties questionnaire (SDQ)-Self-Report. An analysis of its structure in a multiethnic urban adolescent sample. Journal of Child Psychology and Psychiatry, 52 (9), 1002-1011.

[29] Soto, C. J., John, O. P., Gosling, S. D., \& Potter, J. (2011). Age differences in personality traits from 10 to 65: Big Five domains and facets in a large cross-sectional sample. Journal of personality and social psychology, 100 (2), 330.

[30] Strube, M., Grimm, G., \& Yarnold, P. R. (2006). Reading and understanding more multivariate statistics. Reliability and generalizability theory. Washington DC: American Psychological Association.

[31] Tononi, G., Boly, M., Massimini, M. \& Koch, C. (2016). Integrated information theory: from consciousness to its physical substrate. Nature Reviews Neuroscience, 17, 450461.
[32] Van den Akker, A. L., Deković, M., Asscher, J., \& Prinzie, P. (2014). Mean-level personality development across childhood and adolescence: A temporary defiance of the maturity principle and bidirectional associations with parenting. Journal of personality and social psychology, 107 (4), 736.

[33] Verhofstadt-Deneve, L., Vyt, A., \& Van Geert, P. L. C. (2003). Handboek ontwikkelingspsychologie: Grondslagen en theorieën [Handbook developmental psychology: Foundations and theories]. Houten: Bohn Stafleu Van Loghum.

[34] Vuyk, M. A., Krieshok, T. S., \& Kerr, B. A. (2016). Openness to experience rather than overexcitabilities: Call it like it is. Gifted Child Quarterly, 60 (3), 192-211.

[35] Zeidner, M., \& Shani-Zinovich, I. (2011). Do academically gifted and nongifted students differ on the Big-Five and adaptive status? Some recent data and conclusions. Personality and Individual Differences, 51 (5), 566-570. 